\title{
Interview: Yvo de Boer
}

\author{
Yvo de Boer, executive secretary of the United Nations Framework Convention on Climate \\ Change, discusses what world leaders can expect from next month's UN climate conference in \\ Poznan, Poland. The summit marks an important stepping stone to talks at the end of 2009 in \\ Copenhagen, where countries have agreed to strike a new climate accord to follow on the heels \\ of the Kyoto Protocol. Interview by Amanda Leigh Mascarelli.
}

How do you expect the climate talks in Poznan to further progress toward reaching a post-Kyoto climate deal in Copenhagen? Poznan is going to be a very important transition moment. In 2008, we had four meetings during which governments and international organizations came with a large number of proposals on what they feel should be elements of an agreed outcome in Copenhagen. Then at our last meeting in Accra, Ghana, in August, the chair of that process was asked to pool those ideas into a single compilation document. That's going to be on the table in Poznan. And that basically constitutes the first version of a negotiating document.

This is probably going to be a huge disappointment to many people, but the conference in Poznan is not going to be spectacular. It's a halfway mark between last year's climate summit in Bali and the next one in Copenhagen, and it's not the moment when things will be finalized. But what we can expect from Poznan is a clear sense of direction, strong political guidance from ministers, and a much better sense of how the work needs to be managed in 2009 in order to meet that incredibly tight deadline and deliver the political essentials that Copenhagen must deliver.

\section{Poznan is going to be a very} important transition moment. It's not going to be possible, feasible or necessary to agree every last detail in Copenhagen. But I do believe that you need to have an agreement in Copenhagen that has legs so that you can subsequently work out the details. Otherwise the process will just begin to slip.
It has been suggested that the most plausible outcome for Copenhagen may be an intermediary agreement outlining the key elements of a post- 2012 framework. Do you agree that is a reasonable expectation for Copenhagen, given that the United States will probably not enact its own comprehensive domestic climate package until 2010 and is likely to insist on doing so before signing on to international mandates? I don't think that there was a single country that signed up to a target in Kyoto that already had its domestic policy package in place. So I think it's possible to do a political deal in Copenhagen without having all of the domestic measures in place. And since countries committed, and the US committed, actually, under President Bush at last year's climate summit in Bali to a negotiating process that is supposed to be concluded in Copenhagen in 2009, I really think that it's important that countries stick to that international commitment. Having said that, of course, it's not going to be possible, feasible or necessary to agree every last detail in Copenhagen. But I do believe that you need to have an agreement in Copenhagen that has legs so that you can subsequently work out the details. Otherwise the process will just begin to slip.

Is the current global financial crisis likely to threaten a new global agreement on climate change? And what will be the likely impact of the recent G20 meeting in Washington DC in setting it back on the right track? I don't think it's going to threaten a global agreement on climate change, but it will certainly have an impact on it. We have an economic crisis, and that's led to scarcity of capital on international markets. It's led to a drop in oil prices, which is bad for renewable sources of energy and bad for investments in energy efficiency.

At the same time, what I found very encouraging from the G20 summit is that leaders were saying, 'look, we should not

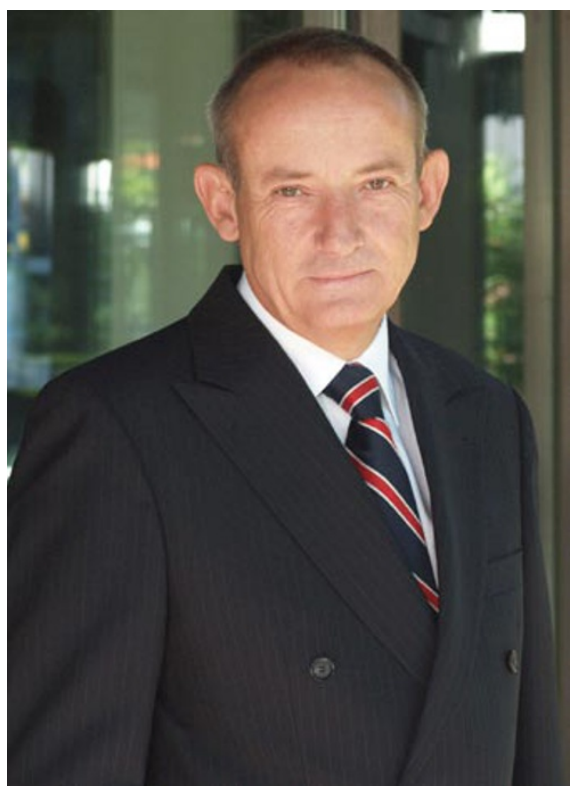

get into a situation whereby this financial crisis causes us to ignore other major global issues like climate change, poverty and hunger.'

What bearing does the election of Barack Obama have on the likelihood of a postKyoto deal being reached by the end of 2009? It has a huge bearing. In Bali, developing countries and, in fact, everyone in the room was calling on the United States to show leadership on this issue, and the United States joined the consensus in Bali. It makes no sense whatsoever to develop an international climate change regime that does not involve the United States. So I think that everyone is looking forward to President-elect Obama's engagement in all of this. He's committed to showing leadership, and that's what the world needs.

China recently proposed that the UNFCCC should set up an intergovernment agency to help developing countries tackle climate change. What do you think about that 
suggestion, and is it likely to be on the table at Poznan?

What China has proposed ... is, first of all, a new facility that would be focused on technology transfer. And secondly, China supports a broader proposal from the group of developing countries to create a new financial mechanism under the Convention, since verifiable support for developing countries is at the heart of what was agreed in Bali. And certainly those proposals will be on the table in Poznan.

\section{What is the best scenario for finding} common ground between the stringent emissions reductions that Europe is calling for and the more measured goal that the US is aiming for?

I think that the language agreed to at last year's conference in Bali calls for a comparability of efforts amongst industrialized countries. President-elect Obama has formulated a long-term goal and has said that he's committed to returning emissions to 1990 levels by 2020 . Europe has its goal of reducing emissions to $20-30$ per cent below 1990 levels by 2020. Australia is working on a mid-term and long-term goal. Canada has some proposals on the table. I think it would be really constructive if we could just put all of those proposals together and begin to look at them in terms of comparability of effort: what are countries proposing, what are their national circumstances, and how easy or tough is it for them to move forward? Plus, most importantly, how can international cooperation - and how can a Copenhagen agreement - make it possible for them to be more ambitious collectively than they could be on their own?

Published online: 27 November 2008 doi:10.1038/climate.2008.128

Amanda Leigh Mascarelli is a freelance science writer in Denver, Colorado.

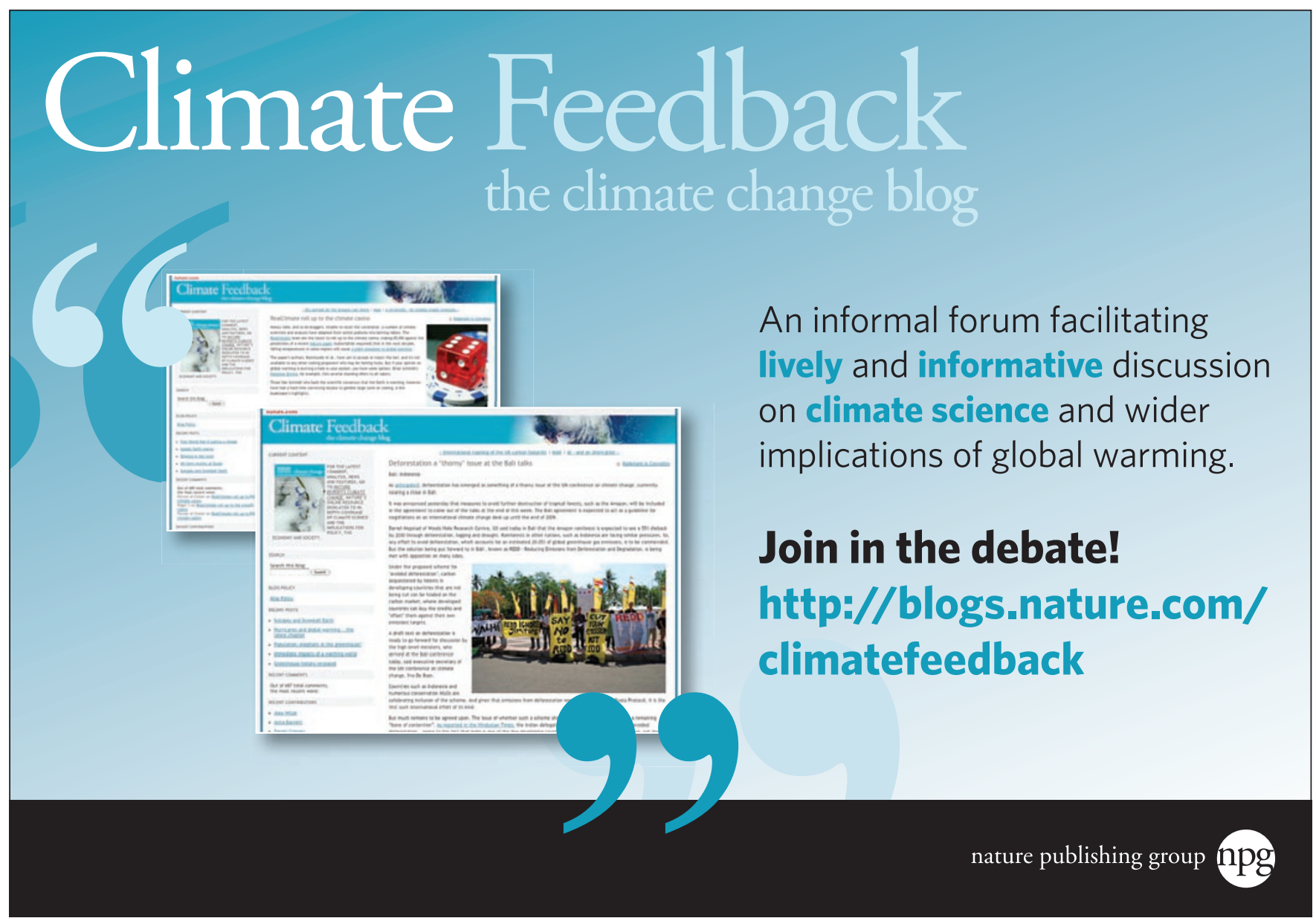

